\title{
ROJAS ZORRILLA Y OTROS DRAMATURGOS ESPAÑOLES EN LA BIBLIOTECA DE UN SEFARDÍ DE GIBRALTAR DEL SIGLO XVIII
}

\author{
PALOMA DÍAZ-MAS \\ Instituto de la Lengua Española, CSIC
}

\section{RESUMEN}

El manuscrito Ms 22090 de la Biblioteca Nacional de Madrid es el Cancionero de Abraham Israel, una colección de poemas y canciones en español, inglés y lingua franca recogidos por un sefardí de Gibraltar desde 1761 hasta 1770. En el manuscrito se incluye también, bajo el título «Notta de las comedias que tengo en libros» una breve lista de 36 titulos de obras teatrales españolas del siglo XVII, entre ellas Progne y Filomena, de Rojas Zorrilla. En este artículo identificamos las obras mencionadas en esa lista, con especial atención a las ediciones sueltas impresas en el siglo XVIII, y analizamos cómo los judíos de Gibraltar se convirtieron desde época temprana en un puente entre la cultura española peninsular moderna y la de los sefardíes de Marruecos, lo cual contribuyó a la rehispanización de la lengua y la cultura de los sefardíes marroquíes, que culminó en el siglo xx.

Palabras clave: Rojas Zorrilla, teatro, sefardíes, Gibraltar, siglo XVIII, comedias sueltas.

\section{ABSTRACT}

The manuscript Ms 22090 preserved in the National Library in Madrid is the Cancionero de Abraham Israel, a collection of poems and songs in Spanish, English and lingua franca collected by a Sephardic Jew of Gibraltar from 1761 to 1770 . The manuscript also included under the title «Notta de las comedias que tengo en libros» ('list of the plays I have in books'), a small list of 36 titles of $17^{\text {th }}$ Century Spanish plays, one of whose is Rojas Zorrilla's Progne y Filomena. The aim of this article is to identify the plays cited in that list, paying special attention to the editions along the $18^{\text {th }}$ century, and to analize how Jews of Gibraltar become from early times a link between Spanish modern culture and Sephardic Jews settled in Morocco, and contributed to the re-hispanization of Morrocan Sephardic language and culture that reach its highest point in the $20^{\text {th }}$ century. sueltas.

Key words: Rojas Zorrilla, theatre, Sephardic Jews, Gibraltar, $18^{\text {th }}$ Century, comedias

En la Biblioteca Nacional de Madrid se conserva el Cancionero de Abraham Israel, un manuscrito compilado entre 1761 y 1770 por un sefardí de Gibraltar así llamado ${ }^{1}$.

1 Tiene la signatura Ms 22090 y procede de la colección de sir Thomas Phillipps, que fue subastada en distintas etapas por sus sucesores. Para la biblioteca de este lord 
Se trata de un librito en octavo, encuadernado, en el que su poseedor fue autografiando una serie de textos poéticos (la mayoría, cantables, ya que abundan las indicaciones del estilo de «Al caballo» $\mathrm{o}$ «Al tono de el Caballo», «folías», «seguidillas», «seguidillas a la prusiana», etc.) que debía de saberse de memoria, aunque es posible también que algunos de los poemas fuesen compuestos por Abraham Israel, quizás como contrafactum de otros que conocía.

Entre las composiciones abundan las seguidillas, forma poético-musical muy en boga en la tradición española (y, especialmente, en la meridional) de la época, aunque también hay algunos romances y composiciones españolas en otras formas métricas, cuatro poemas en inglés (uno de ellos, un himno masónico), uno en una especie de lingua franca italianizante y cuatro cantos tradicionales sefardíes que muestran ciertos rasgos del dialecto judeoespañol de Marruecos e incluyen algunos hebraísmos (son un romance sobre Jacob hasta ahora desconocido ${ }^{2}$, dos cantos para la festividad judía de Simhat Torá $^{3}$ y el inicio del romance de las Hermanas reina y cautiva ${ }^{4}$ ). Pero, con la excepción de esos cantos tradicionales sefardíes, el resto de las composiciones son representativas, tanto por su contenido y su estilo como por sus características linguiísticas, de la lírica andaluza del siglo XVIII. Por consiguiente, en su lengua y en sus gustos poéticos, Abraham Israel se nos muestra como un sefardí muy influido por la cultura española peninsular del momento. Sobre ello volveremos más adelante.

Poco sabemos, por otra parte, del autor-compilador del manuscrito. Recuérdese que Gibraltar fue cedido a Gran Bretaña por España en el Tratado de Utrech de 1713, como compensación por la ayuda prestada por los ingleses al bando ganador de la Guerra de Sucesión; aunque en el Tratado se hizo constar el compromiso de que nunca habitasen ni tuviesen viviendas en la ciudad musulmanes y judíos, la presencia de judíos en Gibraltar data ya de 1721, a raíz de una firma de un tratado entre Gran Bretaña y el reino de Marruecos, por el cual se reconocía a los naturales de cada uno de esos dos países el derecho a residir en el otro; ello propició el asenta-

inglés, véase HoOK 2004; agradezco al profesor Hook el haberme proporcionado información sobre la procedencia del manuscrito y documentación sobre sus avatares. Una descripción del contenido del cancionero puede verse mi artículo de 2006. El presente trabajo es producto del proyecto de investigación HUM2006-03050 «Los sefardíes ante sí mismos y en sus relaciones con España».

${ }^{2}$ Lo publico en mi artículo «Une nouvelle ballade sur le patriarche Jacob dans un manuscrit séfarade de Gibraltar au XVIII ${ }^{\mathrm{e}}$ siècle», en prensa para la revista YOD.

${ }^{3}$ Uno de ellos un romance, y otro la copla zejelesca de Las tablas de la Ley. Una edición del texto de esta última podrá verse en mi artículo «Una versión de la copla Las tablas de la Ley en un manuscrito dieciochesco de la zona del Estrecho», en prensa para el Homenaje a Iacob M. Hassán.

${ }^{4}$ Para la identificación de este romance y otras versiones recogidas, véase ARMISTEAD 1978, núm. H1. 
miento de judíos marroquíes, la mayor parte sefardíes procedentes de las ciudades del Norte de Marruecos; aunque la comunidad judía gibraltareña no se constituyó como tal hasta 1749 . Israel es todavía un apellido existente entre los judíos de Gibraltar, y parece ser que proviene de una familia de Tetuán que se asentó en la plaza muy tempranamente y cuyos miembros mantuvieron estrechas relaciones con la comunidad sefardí de Londres; por tanto, lo más probable es que nuestro Abraham Israel pertenezca a esa familia, y quizás hubiese nacido ya en Gibraltar ${ }^{5}$; deducimos que era un hombre joven cuando empezó a compilar su cancionero.

Por las anotaciones insertas en el propio manuscrito, su propietario empezó a copiarlo a principios de mayo de 1761 y siguió apuntando composiciones en él hasta por lo menos 1770, que es la última fecha que aparece en una anotación de h. 116r, aunque luego hay unos pocos textos en hojas posteriores, que no sabemos si fueron copiados inmediatamente después o transcurrido algún tiempo; incluso llevó el manuscrito consigo durante un largo viaje, ya que en $\mathrm{h}$. 114v encontramos la anotación «Escrito en la mar grande 7 sep[tiemb]re de / 1769 / En my pasaje de Gibraltar p[ara] / Londres» y luego, en h. 117v, «La mar de Biscaya, Viernes / las 5 de la tarde del dia [blanco] de / agosto de 1770 /viniendo de Londres a Gibraltar». Es precisamente a la vuelta de ese viaje a Londres cuando Abraham Israel pareció perder interés por su cancionero, ya que a continuación deja una serie de páginas en blanco, desde entonces apenas anota textos, y la grafía se hace más descuidada: sólo encontramos después las cuatro composiciones tradicionales sefardíes (hs. $121 \mathrm{v}-124 \mathrm{r}$ ), cinco canciones en castellano y dos en inglés, y en h. 192v empieza una lista titulada «Notta de las Comedias que / tengo a saber En Libros», que abarca hasta la h. 193v.

\section{IDENTIFICACIÓN DE LAS OBRAS DRAMÁTICAS}

La lista contiene los títulos de 36 comedias, agrupadas de seis en seis en bloques numerados del 1 al 6, seguidos de una indicación «7», que parece apuntar a que tenía la intención de anotar un séptimo bloque, aunque lo que sigue está en blanco. La transcripción del fragmento de hs. 192v$193 \mathrm{v}$ es la siguiente:



${ }^{5}$ Datos sobre la familia Israel de Gibraltar (entre los cuales hay un Abraham Israel que podría ser el nuestro), en ABECASSIS 1991, p. 110. Doy las gracias a la profesora Annette Bennaim por haberme puesto sobre la pista del libro de Abecassis. 
N. 1. Los Empeños de Vn acazo

La Fiansa satisfecha

Amor Honor y poder -

Esto sy que es negosiar -

El mas heroico silensio -

Los Cabellos de absalom

N. 2. Progne y filomena

Lorenso me llamo -

La Perla de Ingalaterra

no puede ser guardar Vna muxer

La misma Consiensia acuza

Los Amantes de Teruel

N. 3. Don Juan de Espina en Su Patria

Don Juan de Espina en milan

La fuerza Las timosa

La Confusion de Vn Jardin

El Defensor de Su agravio

La Vanda de Castilla y duelo etc.

N. 4. Emnendar Yerros de amor

El Conde Lucanor -

La Dama Presidente

Primero es la honra

no hay vida como la honra

Mudansas de la fortuna y etc.

N. 5. Hasta el fin Nayde es dichoso

Darlo todo y no dar nada -

Antes que todo es my Dama

El Hercules de Ocaña -

No hay Contra vn Padre Razon

Industrias Contra finezas -

N. 6. Leonsio y Montano

Mentir y mudarse avn tiempo etc

La Vida es Sueño -

El Juramento ante Dios etc

La Xarratiera de Ingalaterra

N. 7. [En blanco]

El Estudiante Pantoja -

Se trata, por tanto, de un listado de obras teatrales, que Abraham Israel debía de tener en su biblioteca en volúmenes encuadernados (a eso se referirá la indicación «tengo en libros»). En una primera lectura ya saltan a la vista algunos conocidos títulos de dramaturgos españoles del siglo XVII, entre ellos uno que corresponde con el de una obra de Rojas Zorrilla: Progne y Filomena, sobre el mito clásico de las hermanas convertidas en gorrión y ruiseñor, que ya aparece en las Metamorfosis de Ovidio y tuvo larga fortuna en las letras universales. Aunque Guillén de Castro escribió una obra con el mismo tema y título, lo más probable es que la que había en la biblioteca de Abraham Israel fuese la de Rojas, que parece haber alcanzado bastante fortuna editorial en el siglo XVIII. 
Por otra parte, no hemos podido localizar ediciones en que esas obras de dramaturgos áureos aparezcan agrupadas como se enumeran en el manuscrito sefardí, por lo que deducimos que lo que tenía Abraham Israel eran seis volúmenes — por lo menos: quizás siete o más, aunque sólo enumeró el contenido de seis- facticios, producto de la encuadernación de seis comedias sueltas en cada volumen.

Cabe preguntarse cómo llegaron esas comedias españolas a manos de un sefardí de origen marroquí asentado en Gibraltar. Debió de adquirirlas en Gibraltar mismo o en alguna ciudad andaluza cercana, a menos que sus viajes o los de sus familiares - por motivos de negocios, ya que los judíos de Gibraltar se dedicaban mayoritariamente al comercio- le llevasen a otros lugares de la Península Ibérica, donde pudo adquirir impresos; también es posible que parte de las comedias las recibiese de miembros de su familia de la generación anterior, asentados en Gibraltar desde los años 20 del siglo. En todo caso, a juzgar por los datos sobre ediciones de esas comedias que hemos podido recabar, no parece que Abraham Israel se surtiese de los productos de una sola imprenta ni de un solo lugar: ya sea que las comprase a libreros, a vendedores ambulantes, en depachos o por la vía que fuese, parece que debía de tener comedias sueltas impresas en diversas localidades, como Madrid, Barcelona, Valencia, Sevilla, y quizás también Valladolid o Salamanca, ya que no todos los títulos mencionados se documentan en la producción de una misma imprenta.

En la lista que sigue hemos intentado identificar cada una de las obras que menciona, con su autor, documentando, sin ánimo de exhaustividad, las ediciones sueltas de esa comedia impresas en el siglo XVIII que se encuentran en el Catálogo Colectivo del Patrimonio Bibliográfico Español y cuyos ejemplares, por tanto, pueden consultarse en bibliotecas españolas. Entre paréntesis cuadrados indico la referencia de ese catálogo, separando con punto y coma las ediciones de cada imprenta distinta. Al final de cada párrafo ofrezco también, a título orientativo, la referencia de la comedia en el catálogo de Urzáiz 2002. En los títulos, mantengo la grafía del manuscrito, pero numero las comedias por número de bloque en el ms. y orden dentro del bloque (por ejemplo, 1.1 es la primera comedia que aparece mencionada en el primer bloque de títulos del manuscrito, y así sucesivamente).

1.1. Los Empeños de Vn acazo: Los empeños de un acaso es una obra que se publicó en la Sexta parte de las comedias de Calderón de la Barca, aunque Urzáiz considera falsa la atribución (según él, es la misma que Los empeños que se ofrecen, de Juan Pérez de Montalbán). En todo caso, con el título en que aparece en nuestro manuscrito y atribuida a Calderón se editó varias veces suelta en el siglo XVIII: por José Padrino, impresor activo en 
Sevilla ca. 1748-1775; por Pedro Escuder en Barcelona ca. 1760; por la viuda de Joseph de Orga en Valencia, 1770; y por Francisco Suriá y Burgada, activo en Barcelona ca. 1770-1805, además de alguna impresión que nos ha llegado sin lugar, sin año y sin nombre del impresor [para la Sexta parte de las comedias de Calderón, cfr. CCPB000496608-2 y CCPB000065799-9; para las impresiones como suelta, CCPB000384192-8; CCPB000404410-X; CСРB000430772-0; CСРB000321284-X у ССРB000393330-X; CCPB000657646-X. Urzáiz 185 y 508]

1.2. La Fiansa satisfecha: es sin duda la comedia de Lope de Vega La fianza satisfecha, que en el siglo XVIII fue impresa por lo menos por Antonio Sanz en 1729 y 1756; sin año en la imprenta de la Santa Cruz, de Salamanca (activa entre 1725 y 1775); y en la imprenta de la Real y Pontificia Universidad de Cervera en 1772, con motivo de una representación celebrada el 4 de septiembre del mismo año [cfr. CCPB000548469-3 y CCPB000657253-7; CCPB000531390-2; CCPB000397423-5. Urzáiz 508 y también 186].

1.3. Amor Honor y poder: corresponde al título de una comedia de Calderón, que imprimieron Antonio Sanz en Madrid, 1732 y 1754; y Francisco Suriá y Carlos Sapera en Barcelona, 1763 [cfr. CCPB000566427-6 у CCPB000321353-6; CСРB000321354-4. Urzáiz 180].

1.4. Esto sy que es negosiar: se imprimió varias veces en Madrid «en la librería y lonja de comedias de Doña Theresa de Guzmán»: suelta, sin año y bajo el título de «Esto si que es negociar, comedia sin fama del maestro Tirso de Molina», y por la misma Teresa de Guzmán en la parte primera de las comedias de este autor, en 1734 [cfr. CCPB000322376-0 y CCPB000657237-5. Urzáiz 628].

1.5. El mas heroico silensio: El más herocio silencio es obra de Antonio Folch de Cardona que, además de incluirse en la Parte XXI de las Comedias nuevas escogidas de los mejores ingenios de España (Madrid, 1663), se imprimió suelta en Valencia, por la viuda de Joseph de Orga, en 1766 [cfr. CCPB000042400-5; CCPB000321490-7. Urzáiz 628].

1.6. Los Cabellos de absalom: el famoso drama bíblico de Calderón - que otros atribuyen a Tirso de Molina - se imprimió suelto en Barcelona, en la imprenta de Francisco Suriá, en 1766 [cfr. CCPB000143681-3 y CCPB000321682-9. Urzáiz 182, y también $628,631]$.

2.1. Progne y filomena: aunque hay una comedia del mismo título de Guillén de Castro, que se publicó en la Primera parte de las comedias de este autor (Valencia: Felipe Mey, 1618), lo más proba- 
ble en este caso es que se trate de la Progne y Filomena de Francisco Rojas Zorrilla, que se publicó en la Parte primera de sus comedias (Madrid: Lorenzo García de la Iglesia, 1680) y tuvo por lo visto mayor fortuna editorial que la de Guillén de Castro en el siglo XVIII, durante el cual se reeditó varias veces suelta: por Antonio Sanz en Madrid, 1744; por Joseph Padrino, activo en Sevilla ca. 1748-1775; en Barcelona, por Pedro Escuder en 1757 y luego por Francisco Suriá y Burgada, activo entre 1770 y 1805; «En Valencia: en la Imprenta de los hermanos Orga» en 1792; y fue además incluida por Tomás Sebastián y Latre en su Ensayo sobre el teatro español, publicado en Zaragoza, en la Imprenta del Rey, 1772 y reimpreso en Madrid, en la imprenta de Pedro Marín, en 1773 [cfr. para la de Guillén de Castro CCPB000038988-9; para la de Rojas, CCPB000348325-8, CCPB000321745-0, CCPB000657251-0, CСРВ000321744-2, CCPB000321745-0, ССРВ000435598-9; para el Ensayo de Latre, CCРB000060639-1， CСРВ000246334-2， ССРВ000744360-9. Urzáiz 239 y 571; véanse también 79 y 115].

2.2. Lorenso me llamo: debe de tratarse de Lorenzo me llamo y carbonero de Toledo, de Juan de Matos Fragoso, que, además de incluirse en la Parte XXVI de las Comedias nuevas escogidas de los mejores ingenios de España (Madrid: Francisco Nieto, 1666), se imprimió suelta en Madrid, por Antonio Sanz, en 1754; y en Barcelona, por Juan Nadal, en 1775 [cfr. CCPB000037237-4 y CCPB000042406-4; CCPB000242831-8; CCPB000670108-6. Urzáiz 429].

2.3. La Perla de Ingalaterra: debe de ser La perla de Inglaterra y peregrina de Hungría, impresa varias veces como anónima («de un ingenio de esta Corte») en el siglo XVIII: en Valladolid, por Alonso de Riego (activo entre 1700 y 1763), atribuida a «un ingenio de la Universidad de Salamanca»; en Madrid, por Antonio Sanz, en 1744 y 1756; en Sevilla, por Joseph Padrino, activo entre 1748 y 1775; y en Valencia, en la imprenta de Joseph y Thomás de Orga, en 1780 [cfr. CCPB000670670-3 ; CCPB000321626-8 y CCPB000657473-4; ССРВ000321276-9; ССРВ000231096-1 у CCPB000436135-0. Urzáiz 112].

2.4. No puede ser guardar Vna muxer: es la famosa obra de Agustín Moreto No puede ser, el guardar a una mujer que, además de incluirse entre las comedias de capa y espada del Theatro hespañol de Vicente García de la Huerta (Madrid: en la Imprenta Real, 1785), se imprimió suelta en Valencia, por la viuda de Joseph de Orga, en 1765 [cfr. CCPB000463700-3; ССРB000145753-5. Urzáiz 471; véanse también 671 y 709]. 
2.5. La misma Consiensia acuza: también de Moreto, La misma conciencia acusa se imprimió varias veces en el siglo XVIII: hay ediciones de la Imprenta de Santa Cruz, de Salamanca (activa entre 1725 y 1775); de Barcelona, por Francisco Suriá y Burgada, activo entre 1770 y 1805; en Valencia por Joseph y Thomás de Orga en 1781; y dos sin lugar ni año que, por la tipografía, parecen también dieciochescas. Además, la edición de la Primera parte de las comedias de Moreto que se proclama impresa en Valencia por Benito Macè en 1676 es al parecer falsificada y facticia, hecha de la recopilación de varias comedias sueltas impresas en el XVIII (entre ellas, ésta) [cfr. CCPB000670643-6; CCРB000230990-4 у CCPB000543919-1; CCРB000145751-9 у ССРB000347894-7 ; ССРB000321614-4 у CCPB000347930-7; CCPB000670923-0. Urzáiz 470 y también 430].

2.6. Los Amantes de Teruel: hay comedias con este título de varios autores del siglo XVII: una burlesca de Vicente Suárez de Deza y Ávila se incluye en las obras de este autor impresas en Madrid, por Melchor Sánchez en 1663; hay otra entre las de Tirso de Molina llevadas a la imprenta por su sobrino Francisco Lucas de Ávila (Madrid, Imprenta del Reino, 1635); la de Juan de Yagüe de Salas se publicó suelta en Valencia, por Pedro Patricio Mey, en 1616; pero lo más probable es que en este caso se trate de la obra homónima de Juan Pérez de Moltalbán, que además de aparecer en el Primer tomo de sus comedias (Madrid, Imprenta del Reino, 1635) y de incluirse con su nombre en varias compilaciones de obras de diversos autores (Zaragoza, herederos de Pedro Lanaja, 1652; Lisboa, Pablo Craesbeeck, 1647), se publicó suelta por lo menos dos veces en el siglo XVIII, una sin lugar y sin año y otra en Valencia, por la viuda de Joseph de Orga, en 1765 [cfr. CCPB000040856-5; CCPB000042861-2; CCPB000042808-6; CСРВ000040976-6; CСРВ000042372-6; CСРВ000042377-7; CСРB000322841-X; ССРB000657817-9. Urzáiz 618, 626, 506; y también 60].

3.1. Don Juan de Espina en Su Patria: es una comedia en dos partes, que se atribuye a José de Cañizares (aunque la mayoría de las veces se publicó como anónima «de un ingenio de esta corte»), y que tuvo varias ediciones en el siglo XVIII: la primera parte, en Madrid, por Antonio Sanz, en 1745; y en Salamanca, en la Imprenta de la Santa Cruz, sin año (pero ca. 1750-1765). La primera parte y la segunda, en Sevilla, por Joseph Padrino (activo entre 1748 y 1775) y en Barcelona, por Carlos Sapera, en 1773 [cfr. CCPB000060999-4; CCPB000678696-0; CCPB000321370-6 у ССРВ000321371-4; ССРВ000670209-0 у ССРВ000670214-7. Urzáiz 221; véase también 368]. 
3.2. Don Juan de Espina en milan: se atribuye también a Cañizares; con la indicación «segunda parte», se publicó como anónima («de un ingenio de esta corte») en Madrid, por Antonio Sanz, en 1745 [cfr. CCPB000321389-7. Urzáiz 221 y también 368].

3.3. La fuerza Las timosa: La fuerza lastimosa es una obra de Lope de Vega, de la que en el Catálogo del Patrimonio Bibliográfico Español sólo hemos podido documentar ediciones en la Segunda parte de sus comedias (Barcelona, Sebastián de Cormellas, 1611 y Bruselas, Roger Velpio y Huberto Antonio, 1611) y, suelta, en Madrid, librería de Quiroga, en una época demasiado tardía para Abraham Israel: 1792; sin embargo, Palau da noticia de numerosas ediciones sueltas del siglo XVIII: en Granada, por Nicolás Prieto en 1715; en Sevilla, por Joseph Padrino (activo 1748-1775) y Antonio de Hermosilla (ca. 1725-1738), por Francisco de Leefdael (a principios del siglo XVIII), y luego por su viuda (ca. 1729-1733), y otras sin lugar y sin nombre de impresor [CCPB000037626-4 y CCPB000042735-7; CCРB000042736-5; ССРB000321915-1. Cfr. Palau 355893-4, 355896-355903. Urzáiz 663; véase también 445].

3.4. La Confusion de Vn Jardin: de nuevo se trata de una obra de Moreto, que se publicó suelta varias veces en el siglo XVIII: en Sevilla, por Joseph Antonio de Hermosilla (ca. 1725-1738); y en Salamanca, en la imprenta de la Santa Cruz (ca. 1725-1775). Aparece también en la Tercera parte de las obras de Moreto, supuestamente de Valencia, Benito Macè, 1676, pero en realidad falsificada y facticia, hecha de comedias sueltas impresas en el siglo XVIII [CCPB000322609-3; CCPB000321573-3 у CCPB000670668-1; CCPB000678301-5. Urzáiz 468].

3.5. El Defensor de Su agravio: también de Moreto, es otra de las comedias incluidas en la Tercera parte falsa de Valencia 1676, que a lo largo del siglo XVIII se había publicado varias veces suelta: en Madrid, por Antonio Sanz, en 1748; en Sevilla, a costa de Joseph Antonio Hermosilla (ca. 1725-1738) y por Joseph Padrino (activo 1748-1775); y en Valencia, por Joseph y Thomás de Orga, en 1781 [cfr. CCPB000678301-5; CCPB000656897-1; ССРВ000443486-2; ССРВ000656924-2; ССРВ000145745-4 у CCPB000321421-4. Urzáiz 468]

3.6. La Vanda de Castilla y duelo etc.: La vanda de Castilla y duelo contra sí mismo es una comedia de José de Cañizares, que imprimió suelta en Madrid Antonio Sanz en 1747; hay otra edición que se vendía «en la librería de Juan Pablo González, en la calle de Atocha», pero parece tardía para Abraham Israel, ya que ese librero ejerció entre 1790 y 1800 [cfr. CCPB000670610-X; CCPB000656797-5. Urzáiz 221]. 
4.1. Enmendar Yerros de amor: obra de Francisco Jiménez de Cisneros que, además de incluirse en la Parte treinta y ocho de comedias nuevas escritas por los mejores ingenios de España (Madrid, Lucas Antonio de Bedmar, 1672) y en unas Comedias varias de distintos autores, sin lugar ni año, se imprimió suelta en Sevi1la, «en la imprenta de la Universidad, a costa de don Joseph Navaro y Armijo y la viuda de don Diego López de Haro», entre 1735 y 1759 [cfr. CCPB000042420-X; CCPB000460715-5; CCPB000674432-X. Urzáiz 376].

4.2. El Conde Lucanor: es obra de Pedro Calderón de la Barca, que en el siglo XVIII publicó suelta en Barcelona Francisco Surià y Burgada, activo entre 1770 y 1805 [cfr. CCPB000321263-7 y CCPB000321409-5. Urzáiz 183].

4.3. La Dama Presidente: se trata de una comedia de Francisco de Leyva Ramírez de Arellano, que se imprimió suelta en Madrid, por Antonio Sanz, en 1748; en Salamanca, en la Imprenta de la Santa Cruz; en Sevilla, por Joseph Padrino (ca. 1748-1775) y en Valencia, por Joseph y Thomás de Orga en 1776 [CCPB000632773-7, ССРВ000656908-0 у ССРВ000656945-5; ССРВ000670173-6 ; ССРВ000230986-6; ССРВ000321588-1 у CCPB000321588-1. Urzáiz 392] .

4.4. Primero es la honra: esta comedia de Moreto se imprimió suelta en Madrid, por Antonio Sanz, en 1753; en Sevilla, por Joseph Padrino, ca. 1748-1775; y en Valencia, por la viuda de Joseph de Orga, en 1761; hay otra edición más tardía, de la librería Quiroga, 1792. Y se incluyó en la edición falsa y facticia atribuida a Benito Macé [CСРВ000347919-6; CCРB000321742-6; CCPB000145756-X; CCPB000657362-2; CCPB000670950-8. Urzáiz 471].

4.5. No hay vida como la honra: debe de tratarse de la comedia de Juan Pérez de Montalván, de la que no hemos podido documentar más que una edición suelta, sin lugar ni año, del siglo XVIII. Con anterioridad se había publicado junto con otras del mismo autor en sus Exemplos morales, humanos y divinos (Huesca, Pedro Bluson, 1633), reeditados en Sevilla, imprenta y librería de los Gómez, 1736 [cfr. CCPB000321919-4; CСРB000040947-2; CCPB000173910-7. Urzáiz 510, y 673 para una versión burlesca de Lope].

4.6. Mudansas de la fortuna y etc.: debe de tratarse de Mudanzas de la Fortuna y firmezas del amor, de Cristóbal de Monroy y Silva, que se imprimió suelta y en Salamanca, en la Imprenta de la Santa Cruz, entre 1725 y 1775; y en Valencia, por la viuda de Joseph de Orga, 1768 [cfr. CCPB000670666-5; CCPB000321714-0. La 
referencia de Urzáiz 528 a una obra de Quevedo con este subtítulo no parece tener que ver con la comedia mencionada aquí].

5.1. Hasta el fin Nayde es dichoso: Hasta el fin nadie es dichoso es otra obra de Moreto, que (además de aparecer en la Primera parte de las comedias de este autor, en Madrid, por Andrés García de la Iglesia, 1677), se imprimió suelta en Madrid por Antonio Sanz, en 1751; y en la Imprenta de la Santa Iglesia de Burgos, s.a.. La de Sanz está incluida además en la edición falsa y facticia de la Primera parte de las comedias de Moreto supuestamente de Valencia, Benito Macè, 1676 [cfr. CCPB000033721-8; CCPB000347913-7; CCPB000670672-X; СCРB000670672-X. Urzáiz 469].

5.2. Darlo todo y no dar nada: es obra de Calderón que se publicó suelta en Barcelona, primero por Pedro Escuder en 1758 (con el título de Darlo todo y no dar nada. Apeles y Campaspe) y luego por Francisco Suriá y Burgada (ca. 1770-1805); hay también otra edición dieciochesca sin lugar ni año ni nombre de impresor [cfr. CCPB000369064-4; CCPB000321373-0; ССРB000322648-4. Urzáiz 184; para una versión burlesca de Francisco de Lanini y Sagredo, Urzáiz 386].

5.3. Antes que todo es my Dama: también de Calderón, la publicaron suelta en Barcelona Pedro Escuder en 1758, y Francisco Suriá y Burgada (ca. 1770-1805) [cfr. CCPB000322648-4; CCPB000231004X. Urzáiz 181].

5.4. El Hercules de Ocaña: El Hércules de Ocaña es el título de una comedia de Juan Bautista Diamante, que en el siglo XVIII imprimieron suelta en Madrid, Francisco Sanz (ca. 1671-1699) y Antonio Sanz en 174; y en Salamanca la Imprenta de la Santa Cruz (ca. 1777-1785). Urzáiz de noticia de otra homónima de Luis Vélez de Guevara, de la que no hemos encontrado ediciones sueltas [cfr. CCPB000321446-X; CСРB000656959-5 у CСРB000657111-5; CCPB000321451-6. Urzáiz 286 y 702].

5.5. No hay Contra vn Padre Razon: de Francisco de Leyva Ramírez de Arellano, la imprimió en Barcelona Pedro Escuder en 1757; en Valencia, Joseph y Thomás de Orga, en 1775; y, ya de finales de siglo, hay una edición de 1792 que «se hallará en la librería de Quiroga, calle de la Concepción Gerónima» de Madrid [cfr. CCРB000321720-5; CCРB000436196-2; CCРB000436196-2. Urzáiz 393].

5.6. Industrias Contra finezas: otra comedia de Moreto, que (además de incluirse en varias colecciones y partes del siglo XVII) se imprimió suelta en Sevilla, por la Viuda de Francisco Leefdael (ca. 1729-1733) y por Joseph Padrino (ca. 1748-1775); y en Madrid, 
por Antonio Sanz, en 1751; hay también una más tardía de Barcelona, por Juan Serra y Centené, quien ejerció entre 1784 y 1788. Está también en la edición facticia y falsa atribuida a Benito Macé [cfr. CCPB000322542-9; CCPB000714190-4; CCPB000347922-6; CCPB000643058-9; CCPB000670950-8. Urzáiz 470].

6.1. Leonsio y Montano: Leoncio y Montano es el título de una comedia de Diego Figueroa y Córdoba (al parecer, escrita en colaboración con su hermano José), que se incluyó —con otras once de diversos autores- en el Pensil de Apolo (Madrid, Domingo García y Morrás, 1661) y se imprimió suelta por Antonio Sanz (Madrid, 1746) y por Joseph Padrino (Sevilla, ca. 1748-1775) [cfr. CCPB000042393-9; CCPB000321669-1; CCPB000321670-5. Urzáiz 319 y 320].

6.2. Mentir y mudarse avn tiempo etc: se trata de otra comedia de Diego de Figueroa y Córdoba (quizás también escrita en colaboración con su hermano), cuyo título completo es Mentir y mudarse a un tiempo y mentiroso en la corte; se incluyó también en el Pensil de Apolo con la indicación de que «se representó a Sus Majestades en el Buen Retiro»; la imprimió suelta en Madrid Antonio Sanz, 1746 y hay otra edición sin año, de Sevilla, «en la imprenta del Correo Viejo» [cfr. CCPB000042393-9; CCPB000442681-9; CCPB000322963-7. Urzáiz 319 y 320].

6.3. La Vida es Sueño: de la famosa obra de Calderón se conocen varias impresiones como suelta en el siglo XVIII: la más antigua sería una sin indicación de impresor, lugar ni año, pero datable en ha. 1730; y hay otras de Valencia, por la Viuda de Joseph de Orga, 1761; Madrid, «en la librería de Andrés Sotos» (quien ejerció entre 1764 y 1792); Barcelona, por Juan Francisco Piferrer ( $\sin$ año, pero seguramente de la segunda mitad el siglo); y también de Barcelona, por Francisco Suriá y Burgada (ca. 1770-1805) [cfr.CCPB000566424-1; CCPB000670582-0; CCPB000714116-5; CCPB000394962-1; CCPB000321648-9. Urzáiz 196].

6.4. El Juramento ante Dios etc: debe de tratarse de El juramento ante Dios y lealtad contra el amor, de Jacinto Cordero, de la cual hay una edición suelta sin lugar ni año probablemente del siglo XVII y que hubo de tener considerable éxito editorial en el XVIII, ya que hay otras ediciones de Madrid, por Antonio Sanz, 1753; Barcelona, Francisco Suriá y Burgada, ca. 1770; Valencia, Agustín Laborda (ca. 1771) y Joseph y Thomás de Orga, 1781; además de una tardía de la librería Quiroga de Madrid, 1796 [cfr. CCPB000321453-2; ССРB000657800-4; ССРB000671649-0 у CСРВ000321456-7; CCРB000060906-4; ССРВ000657821-7; CCPB000347967-6. Urzáiz 267]. 
6.5. La Xarratiera de Ingalaterra: será La Xarretiera de Ingalaterra, el mayor aprecio del descuido de una dama, de Francisco Bances Candamo que, además de incluirse en sus Poesías cómicas póstumas (Madrid, Lorenço Francisco Mojados, 1722), tuvo varias impresiones sueltas: una que nos ha llegado sin portada, cuyo colofón advierte que «Véndese en Barcelona: en casa de Francisco Aviñó librero» y se ha datado ha. 1704; y otras de Barcelona, Francisco Suriá y Burgada (ca. 1770-1805); y Valencia, Joseph y Thomás de Orga, 1771 [cfr. CCPB000166988-5; CCPB0004465784; ССРB000321651-9; CCPB000657850-0. Urzáiz 152].

6.6. El Estudiante Pantoja: podría tratarse de Las travesuras del valiente Pantoja, de Moreto, que publicaron suelta en Barcelona Thomás Piferrer en 1772, y Francisco Suriá y Burgada s.a. (ha. 1770-1805) y se incluyó también en la edición facticia y falsificada de la Tercera parte de las comedias de Moreto supuestamente de Valencia, Benito Macè, 1676 [cfr. CCPB000321668-3 y CСРВ000671669-5; CСРВ000657286-3; CСРВ000671669-5. Urzáiz 473; véase también 302 para una comedia titulada $E l v a$ liente Pantoja de Antonio Enríquez Gómez, alias Fernando de Zárate].

El PAPEl DEl TEATRO DE los Siglos DE ORO EN LA CUltura de UN SEFARDÍ DE GIBRALTAR

Para concluir, cabe hacer algunas consideraciones sobre la relevancia y el sentido que tiene encontrar una pequeña biblioteca de 36 comedias sueltas de diversos ingenios del teatro español de los Siglos de Oro en manos de un sefardí gibraltareño, de familia originariamente marroquí, en la segunda mitad del siglo XVIII.

Vaya por delante que el Cancionero de Abraham Israel es un testimonio de excepcional interés, dado nuestro escaso conocimiento de la literatura y la cultura literaria de los sefardíes de Marruecos antes de finales del siglo XIX. Mientras que entre los sefardíes orientales la existencia de imprenta judía desde el siglo XVI hasta el XX (con especial actividad en judeoespañol entre el siglo XVIII y las dos primeras décadas del XX) ha permitido que llegasen hasta nosotros numerosas muestras de la literatura religiosa y profana sefardíes orientales, en impresos aljamiados y en la prensa periódica ${ }^{6}$, la inexistencia de prensa judía en Marruecos hasta el mismo siglo $\mathrm{XX}$ ha hecho que nuestro conocimiento de la literatura que produjeron y consumieron los sefardíes norteafricanos nos haya llegado sólo

${ }^{6}$ Para la literatura de transmisión escrita de los sefardíes orientales, véase el manual de ROMERO 1992. 
a través de testimonios muy tardíos: manuscritos de los siglos XIX y XX o manifestaciones orales recogidas recientemente en encuestas de campo.

El cancionero de Abraham Israel es, por tanto, el manuscrito más antiguo que conocemos compilado en lengua románica por un sefardí originario de Marruecos, aunque viviese en Gibraltar. Y, significativamente, lo que recoge mayoritariamente no son muestras de la literatura tradicional judía, de cuño religioso, sino muy profanas manifestaciones de la poesía amorosa y burlesca, del mismo estilo que las que se conocían y cantaban en el resto de la España del siglo XVIII, con las mismas formas métricas, los mismos modos musicales, los mismos temas y hasta la misma lengua, que no es la variedad del judeoespañol marroquí (hakitía) ${ }^{7}$ sino un español meridional casi idéntico al andaluz. Sólo las cuatro composiciones sefardíes de hs. $121 \mathrm{v}-124 \mathrm{r}$ tienen rasgos lingüísticos y temáticos específicamente judíos.

Por lo que respecta al teatro, la lista de comedias inserta en el manuscrito (un pequeño catálogo de la biblioteca dramática de su poseedor) nos revela algo sobre las lecturas de este sefardí gibraltareño: son las mismas que las de cualquier curioso lector español de la época.

La mayor estudiosa del teatro sefardí, Elena Romero, ha señalado varias veces ${ }^{8}$ el «total desconocimiento del teatro español de todos los tiempos que han padecido los sefardíes» del antiguo imperio otomano, cuya cultura dramática se nutría de obras de creación propia (normalmente, de temática judía) o traducidas de otras lenguas, como el hebreo y, sobre todo, el francés (y a través de traducciones francesas llegaron también obras escritas originalmente en otras lenguas, como el ruso o el inglés). La afirmación es, desde luego, válida para los sefardíes orientales, pero está claro que entre los del occidente Mediterráneo la situación era muy otra ya desde el siglo XVIII: no nos consta que entre ellos hubiera una actividad teatral (con representaciones y grupos teatrales) como la que hubo en Oriente, pero, por lo visto, algunos sí que leían teatro español.

No cabe olvidar que la familia Israel era originaria de Tetuán, y muy probablemente seguía teniendo relación con miembros de la familia que quedaron al otro lado del Estrecho, lo mismo que la tenían con la comunidad sefardí londinense (a juzgar por los datos del libro de Abecassis antes citado, parece que el propio Abraham Israel acabó casándose en Londres y asentándose a vivir allí). A través de esa red de relaciones familiares (que eran también redes de negocios) debieron llegar a los sefardíes marroquíes muchas influencias de la cultura española peninsular.

En el siglo XX se ha producido ya la casi total rehispanización de los sefardíes del Norte de África, tanto en los aspectos lingüísticos (desaparición de la haketía y adopción del español moderno en su variedad meri-

${ }^{7}$ Para la hakitía sigue siendo fundamental el viejo artículo de BENOLIEL 1926-1952.

${ }^{8}$ Por ejemplo, en su libro de 1992 antes citado, pp. 290-291. 
dional, quedando sólo unos pocos rasgos dialectales en su habla) ${ }^{9}$ como culturales. Suele considerarse que ese proceso de rehispanización de la cultura sefardí de Marruecos comienza con la toma de Tetuán por las tropas españolas en 1860 y la implantación de una administración española en la ciudad hasta 1862; que continúa y se acentúa en el período de las guerras de África y del protectorado español en Marruecos entre 1913 y 1956; y que culmina con la emigración de muchos sefardíes del Magreb a España tras la independencia de Marruecos en ese año. Pero un caso como el de Abraham Israel, gran aficionado a aprender (y quizás componer) seguidillas, que escribía en un español con rasgos más propios del andaluz que del judeoespañol y que atesoraba en su biblioteca unas decenas de comedias de dramaturgos españoles del siglo XVII (entre ellos, Rojas Zorrilla), nos hace pensar que probablemente ese proceso de rehispanización de los sefardíes de la zona del Estrecho de Gibraltar empezó un siglo antes de lo que creíamos.

\section{BIBLIOGRAFÍA CITADA}

Abecassis, José María, Genealogia Hebraica. Portugal e Gibraltar. Sécs. XVII a XX, vol. III. Lisboa, s.d., 1991.

Armistead, Samuel G., El Romancero judeo-español en el Archivo Menéndez Pidal (Catálogo-Índice de romances y canciones). 3 vols. Madrid, Cátedra Seminario Menéndez Pidal, 1978.

BenOliel, José, «Dialecto judeo-hispano-marroquí o Hakitía», Boletín de la Real Academia Española XIII (1926), pp. 209-233, 324-363, 507-538; XIV (1927), pp. 137168, 196-234, 357-373, 566-580; XV (1928), pp. 47-61, 188-223; y XXXII (1952), pp. $255-289$.

Catálogo Colectivo del Patrimonio Bibliográfico Español, recurso en línea: http:// www.mcu.es/bibliotecas/MC/CCPB/index.html

DíAZ-MAS, Paloma, «El manuscrito de Abraham Israel», Miscelánea de Estudios Árabes y Hebraicos. Sección de hebreo 55 (2006), pp. 141-156.

HASSÁN, Iacob M., «De los restos dejados por el judeo-español en el español de los judíos del Norte de África», Actas del XI Congreso Internacional de Lingüística y Filología Románicas, Madrid, 1968, pp. 2127-2140.

Hook, David, «La Biblioteca Phillippica y sus problemas». En La memoria de los libros. Estudios sobre la historia del escrito y de la lectura en Europa y América, Madrid, Instituto de Historia del Libro y de la Lectura, 2004, pp. 403-414.

Palau y Dulcet, Antonio, Manual del librero hispanoamericano, $2^{\mathrm{a}}$ ed., Barcelona, Librería Palau, 1948-1977, 28 vols.

ROMERO, Elena, La creación literaria en lengua sefardí, Madrid, Mapfre, 1992.

URZÁIz TORTAJADA, Héctor, Catálogo de autores teatrales del siglo XVII, Madrid, Fundación Universitaria Española, 2002, 2 vols.

${ }^{9}$ Para los rasgos dialectales del español moderno hablado por sefardíes marroquíes tras la desaparición de la haketía, véase HASSÁN 1968. 